\title{
Calcium evaluation of human fingernail using laser plasma spectroscopy by simultaneously applying addition and modified external standardizations
}

\author{
Sahar Maghsoumi ${ }^{1} \cdot$ Hamidreza Shirvani-Mahdavi $^{1}$ (D)
}

Received: 5 October 2018 / Accepted: 19 December 2018 / Published online: 27 December 2018

(c) The Author(s) 2018

\begin{abstract}
Identification and quantification of human fingernail calcium is demonstrated by laser-induced breakdown spectroscopy (LIBS) using the modified external standardization. Since cow's horn and hoof have structures very similar to the fingernail, either of them is individually selected as the matrix of standard samples. In total, 12 standard samples for each matrix are prepared using $\mathrm{CaCO}_{3}$ as the standard substance. In order to achieve accurate calibration curves associated with the method of modified external standard, foremost, the calcium concentration of each of matrices (horn and hoof) is determined by the method of standard additions. The results indicate that there exist $4887 \mu \mathrm{g} / \mathrm{g}(\mathrm{ppm})$ and $4156 \mu \mathrm{g} / \mathrm{g}(\mathrm{ppm})$ of calcium in the pure horn and hoof matrices, respectively. Then, the external calibration curves related to the two matrices are plotted using the information of standard samples. Finally, by the use of signals obtained from LIBS experiment for three different fingernails and inserting their amounts into the calibration curves, the calcium concentration of the fingernails under test is measured to be $10,814 \mu \mathrm{g} / \mathrm{g}(\mathrm{ppm}), 13,106 \mu \mathrm{g} / \mathrm{g}(\mathrm{ppm})$ and $14,974 \mu \mathrm{g} / \mathrm{g}(\mathrm{ppm})$. The difference of the calcium concentrations between three specimens, as will be discussed, may be due to different physical conditions of people who have donated their fingernails.
\end{abstract}

Keywords LIBS $\cdot$ Modified external standardization $\cdot$ Standard additions $\cdot$ Calibration curve

\section{Introduction}

Laser-induced breakdown spectroscopy (LIBS) is a method through which qualitative and quantitative elemental analysis of materials are mainly carried out. Although the first scientific report of laser-induced plasma was published in 1963 [1], it has received considerable research and practical attention since 1980. Quantitative LIBS analysis can be performed by different procedures [2-6]. In most materials, the concentration of one or a few number of elements in the sample is needed to be obtained. In these cases, the calibration-based method (CB-LIBS) is normally more efficient than the other ones. In order to determine the concentration of a specified species in the sample under study by

Hamidreza Shirvani-Mahdavi

hsm@iauctb.ac.ir

1 Photonics Research Laboratory, Department of Physics, Islamic Azad University (Central Tehran Branch), Tehran, Iran
CB-LIBS, one should experimentally establish a suitable standardization, that is, a reliable relationship between the integral intensity $(\bar{S})$ of an appropriate spectral line of the neutral or ionized atom and the concentration $(C)$ related to the analyte. Generally, until now, four types of standardization methods have been commonly utilized: external, internal, addition and addition-internal combinatorial [7-9].

In the external standardization, not only standard samples are prepared and analyzed separately from the target (the sample under study without any additional materials), but also any difference between the matrix of the standards and the target's matrix has no effect on the final result [10]. When the physical and chemical matrix effects are important in the final outcomes, an effort is made to match the matrix of the standards to that of the target. In this case, one way for matrix matching is the selection of a matrix with features much similar to the target's matrix. This adroit technique which we call it modified external standardization, to a great extent, eliminates the problems caused by the matrix [11]. In cases in which the target's matrix is unknown, only possible way to overcome the matrix effects is to conduct the 
standardization in the target. This is known as the addition standardization [12].

The successful application of an external standardization depends on the analyst's ability to handle standard samples and target, reproducibly. When a procedure cannot be controlled to the extent that all standard samples and target are treated equally, the accuracy and precision of the standardization may suffer. In this case, an external standardization results in a determinate error. Nevertheless, a standardization is still possible if the analyte's signal is referenced to a signal generated by another species that has been added at a fixed concentration to all standard samples and target. The added species, which must be different from the analyte, is called an internal standard; and the method applied in this case is known as the internal standardization [13]. Since the analyte and the internal standard in any standard sample or target receive the same treatment, the ratio of their signals will be unaffected by any lack of reproducibility in the procedure. In order to simultaneously overcome matrix effects and problems related to the irreproducibility which more often affect final results of the measurement and, consequently, cause some serious determinate errors, one can apply combination of addition and internal standardization methods, named addition-internal combinatorial standardization [9].

Keratins refer to a group of insoluble and filamentforming proteins produced in certain epithelial cells of vertebrates; they belong to the family of fibrous structural proteins, and based on physical character, histology and chemical composition, can be classified into two types: soft and hard. For instance, the outer layer of the epidermis is a type of soft keratin, while horn, nail, claw, and hoof are typical examples of hard keratin. Keratinous materials are typically durable, tough and unreactive to the natural environment and mainly provide mechanical support and diverse protective functions in the adaptation of vertebrates to the external environment $[14,15]$. There are different concentrations of mineral elements in the keratinous matrix of human fingernail, which can be affected by several physiological and pathological factors $[16,17]$. On the other hand, owing to the slow growth rate of nails, they contain the history of human life quality and might reflect the long-term patterns of mineral metabolism. Hence, nail is an appropriate organ to monitor nutritional abnormalities, certain diseases and chronic exposure to toxic agents [18].

In this paper, calcium concentration of human fingernail is evaluated by calibration-based laser-induced breakdown spectroscopy according to the modified external standardization. Since the structures of cow's horn and hoof are very similar to the fingernail one, they can be considered as the matrix of standard samples. Since these matrices themselves have some calcium, in order to properly conduct the calibration process, first of all, the amount of calcium in each matrix is obtained from the method of standard additions. Then, two normal calibration curves, one with horn and the other with hoof, are established to measure the fingernail calcium concentrations of three people.

\section{Experimental}

As reported by Micro Trace Minerals Laboratory and some other scientific references, there are typically about 60 elements in the human fingernail [19-21]. Calcium, the structural element, is the most abundant mineral in the fingernail [19], as is in the body. In order to measure the concentration of calcium in the fingernail, due to the existence of a significant number of elements in this organ, the most appropriate method is calibration-based LIBS. But human fingernail is normally available as clippings, and consequently, it cannot be easily utilized to prepare suitable standard samples. On the other hand, since the main material of the fingernail and cow's horn and hoof is keratin, one can expect that cow's horn and hoof be very suitable as the matrix of standard samples.

\section{Sample preparation}

So as to fabricate standard samples, cow's horn and hoof were used as the matrix. First of all, after a good washing and cleaning, they were converted into powder form by a metalworking flat file. Then, to be finer and more uniform, they were ground by a planetary mill (from Fritsch) with the speed of $300 \mathrm{rpm}$ and over a 4-h period. Two twelve-sample sets, one from the horn, and the other from the hoof, as the matrix, were fabricated with different masses of $\mathrm{CaCO}_{3}$ (Calcium carbonate, powder v.p. from Chem-Lab NV) as the source of calcium (analyte). The amount of $\mathrm{CaCO}_{3}$, that henceforth referred to as "standard substance" $\left(M_{\text {st.sub }}\right)$, was so selected that the concentrations of $\mathrm{Ca}$ extended in the range of approximately $0.2-2.2 \mathrm{wt} \%$ (Table 1 ).

All masses were measured by an analytical balance (Mettler Toledo) with the precision of four decimal places. For each sample, the combination of sub-micro powders of the matrix and calcium carbonate were put into a vial and mixed together well by shaking the vial for $5 \mathrm{~min}$. Then, the samples were converted to the form of cylindrical tablets under 300 bar pressure by using a custom-made press mold designed for this purpose (Fig. 1).

\section{Laboratory setup}

Figure 2 indicates a schema of the LIBS experiment utilized in this research. The Q-switched, Nd:YAG pulsed laser $(\lambda=1064 \mathrm{~nm}$, from Quantel) generates a laser pulse with duration and energy of $6 \mathrm{~ns}$ and $26 \mathrm{~mJ}$, respectively. The 
Table 1 Specifications of the standard samples and the measured signals relevant to them

\begin{tabular}{|c|c|c|c|c|c|c|c|c|c|c|}
\hline $\begin{array}{l}\text { Standard } \\
\text { Sample }\end{array}$ & $\left(M_{\text {st.sub1 } 1}\right)_{j}(\mathrm{~g})$ & $\left(M_{\text {matrix } 1}\right)_{j}(\mathrm{~g})$ & $\left(M_{\mathrm{st} 1}\right)_{j}(\mathrm{~g})$ & $\left(\bar{S}_{\mathrm{A}-\mathrm{st} 1}\right)_{j}$ (a.u. $)$ & $\frac{\left(\bar{S}_{\mathrm{A}-\mathrm{st} 1}\right)_{j}}{\overline{\mathrm{S}}_{\mathrm{A} \text {-matrix } 1}}$ & $\left(M_{\text {st.sub } 2}\right)_{j}(\mathrm{~g})$ & $\left(M_{\text {matrix } 2}\right)_{j}(\mathrm{~g})$ & $\left(M_{\mathrm{st} 2}\right)_{j}(\mathrm{~g})$ & $\left(\bar{S}_{\mathrm{A}-\mathrm{st} 2}\right)_{j}$ (a.u. $)$ & $\frac{\left(\bar{S}_{\mathrm{A}-\mathrm{s} 2}\right)_{j}}{\bar{S}_{\mathrm{A}-\mathrm{matrix} 2}}$ \\
\hline 1 & 0.0000 & 1.5000 & 1.5000 & 304.042 & 1.0000 & 0.0000 & 1.5000 & 1.5000 & 286.185 & 1.0000 \\
\hline 2 & 0.0074 & 1.4927 & 1.5001 & 660.478 & 2.1723 & 0.0075 & 1.4926 & 1.5001 & 646.249 & 2.2582 \\
\hline 3 & 0.0152 & 1.4850 & 1.5002 & 749.039 & 2.4636 & 0.0150 & 1.4850 & 1.5000 & 750.050 & 2.6209 \\
\hline 4 & 0.0227 & 1.4775 & 1.5002 & 862.417 & 2.8365 & 0.0226 & 1.4775 & 1.5001 & 859.747 & 3.0042 \\
\hline 5 & 0.0299 & 1.4702 & 1.5001 & 1052.929 & 3.4631 & 0.0300 & 1.4701 & 1.5001 & 966.834 & 3.3784 \\
\hline 6 & 0.0375 & 1.4627 & 1.5002 & 1216.360 & 4.0006 & 0.0375 & 1.4625 & 1.5000 & 1187.863 & 4.1507 \\
\hline 7 & 0.0451 & 1.4551 & 1.5002 & 1269.004 & 4.1738 & 0.0451 & 1.4550 & 1.5001 & 1358.023 & 4.7453 \\
\hline 8 & 0.0524 & 1.4476 & 1.5000 & 1365.417 & 4.4909 & 0.0525 & 1.4476 & 1.5001 & 1465.981 & 5.1225 \\
\hline 9 & 0.0599 & 1.4402 & 1.5001 & 1463.123 & 4.8122 & 0.0599 & 1.4402 & 1.5001 & 1565.773 & 5.4712 \\
\hline 10 & 0.0675 & 1.4326 & 1.5001 & 1570.022 & 5.1638 & 0.0674 & 1.4326 & 1.5000 & 1662.799 & 5.8102 \\
\hline 11 & 0.0749 & 1.4252 & 1.5001 & 1666.222 & 5.4802 & 0.0749 & 1.4253 & 1.5002 & 1762.933 & 6.1601 \\
\hline 12 & 0.0824 & 1.4176 & 1.5000 & 1787.154 & 5.8780 & 0.0824 & 1.4176 & 1.5000 & 1859.689 & 6.4982 \\
\hline
\end{tabular}

Subindices 1 and 2 are candidates for the matrices of horn and hoof, respectively; $\left(M_{\mathrm{st.sub}}\right)_{j},\left(M_{\text {matrix }}\right)_{j}$ and $\left(M_{\mathrm{st}}\right)_{j}$ are the measured masses of the standard substance (CaCO3), the matrix (horn or hoof) and the total material in the jth sample, respectively; $\left(\bar{S}_{\mathrm{A}-\mathrm{st}}\right)_{j}$ and $\bar{S}_{\mathrm{A}-\mathrm{matrix}}$ are the signals of the analyte $(\mathrm{Ca})$ at the wavelength $422.673 \mathrm{~nm}$ in the $j$ th sample and the matrix, respectively

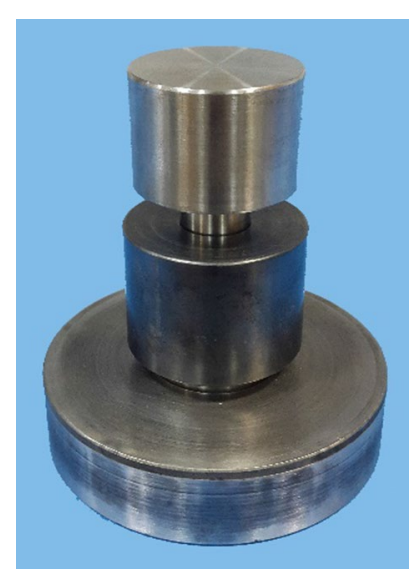

Fig. 1 Custom-made press mold designed for fabricating cylindrical tablets

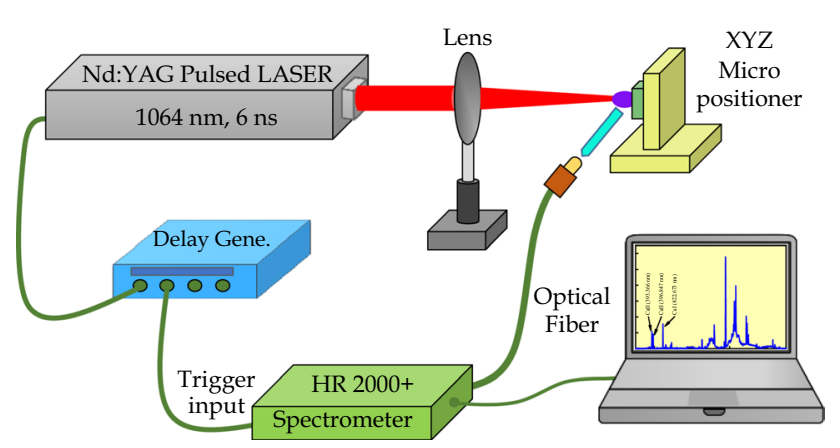

Fig. 2 The schematic setup of LIBS experiment converging lens with the focal length of $150 \mathrm{~mm}$ produces an appropriate power density (intensity) on the sample. For the best adjustment, the sample has been connected to an adjustable XYZ manual micropositioner. The plasma emission spectrum is transmitted via a collimating lens into the optical fiber connected to the spectrometer (HR2000+, from Ocean Optics) with the electronic and optical resolutions of $0.23 \mathrm{~nm}$ and $0.65 \mathrm{~nm}$, respectively. The optical fiber is also placed on an YZ micropositioner attached to a $z$-axis rotation stage which helps acquire an appropriate signal more accurately. The delay generator supplies a suitable gate delay about $2.2 \mu$ s to exclude the background and, to an acceptable extent, to establish a local thermodynamic equilibrium. The trigger signal is provided by the synchronous output of laser power supply. To accurately monitor and control the delay time, we also used the digital oscilloscope (it has not been shown in the figure). So as to remove the surface contamination, the measurement was carried out after applying two laser shots. Due to probable inhomogeneity of the material, five points of each sample were irradiated by laser shots (3 shots for each point) and the average of all spectra (15) was considered to analyze the material.

\section{Results and discussion}

Figure 3 indicates a typical plasma emission spectrum of a fingernail clipping related to a person which is living in Tehran (Iran). There are 25 distinguishable spectral lines in this spectrum (with a signal to noise ratio $(\mathrm{S} / \mathrm{N})$ greater than 4). By considering the restriction arising from the 


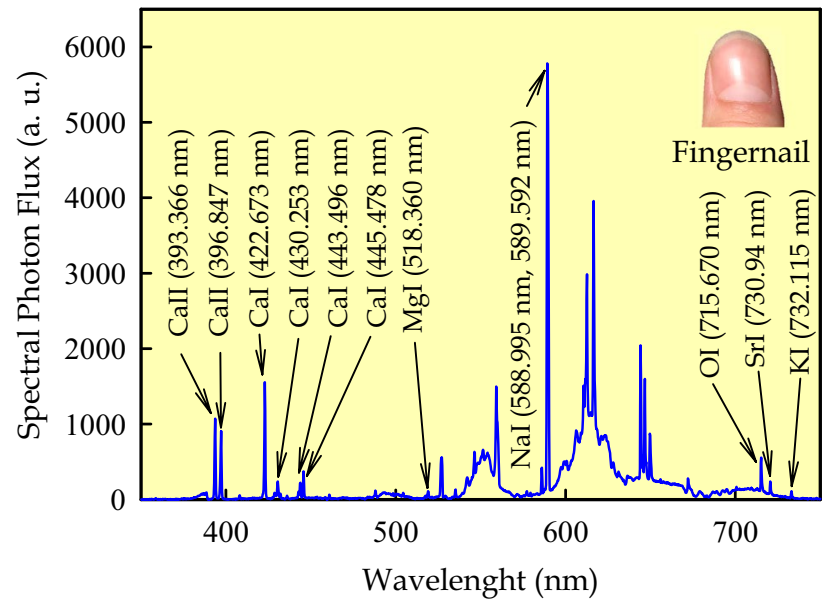

Fig. 3 A typical plasma emission spectrum of a fingernail clipping related to a person recorded by the spectrometer HR2000+ (from Ocean Optics Co.)

Table 2 Spectroscopic parameters of selected spectral emission lines derived from the website of NIST: $E_{\mathrm{u}}, E_{1}$ and $\mathrm{g}_{\mathrm{u}}, \mathrm{g}_{\mathrm{l}}$ are energies and degeneracies of the upper level $\mathrm{u}$ and the lower level $l$, respectively; $A_{\mathrm{ul}}$ is the transition probability between the upper and lower levels

\begin{tabular}{llllll}
\hline Species & Wavelength $(\mathrm{nm})$ & $A_{\mathrm{ul}}\left(\mathrm{s}^{-1}\right)$ & $E_{\mathrm{l}}(\mathrm{eV})$ & $E_{\mathrm{u}}(\mathrm{eV})$ & $\mathrm{g}_{\mathrm{l}}, \mathrm{g}_{\mathrm{u}}$ \\
\hline Ca II & 393.366 & $1.47 \mathrm{e}+08$ & 0.000000 & 3.150984 & 2,4 \\
$\mathrm{Ca}$ II & 396.847 & $1.4 \mathrm{e}+08$ & 0.000000 & 3.123349 & 2,2 \\
$\mathrm{Ca}$ I & 422.673 & $2.18 \mathrm{e}+08$ & 0.000000 & 2.932512 & 1,3 \\
\hline
\end{tabular}

spectral resolution of the spectrometer $(0.65 \mathrm{~nm})$, each spectral line in the experimental spectrum can be related to several elements with different ionization states. Hence, in order to exactly identify the wavelength of spectral lines, in addition to the position of each spectral line compared with others, one way which is helpful may be measurement of the plasma temperature using line pair ratio method. Since the plasma temperature in our experiments is expected to be in the range of $6000 \mathrm{~K}$ to $10,000 \mathrm{~K}$, only spectral lines that lead to the proper temperature can be considered as correct lines. Therefore, by initial inspection and the use of this procedure, one can assert that the spectral lines shown in the spectrum (Fig. 3) are associated with calcium. In this case, the plasma temperature considering the spectral lines of $393.366 \mathrm{~nm}$ and $396.847 \mathrm{~nm}$ was calculated equal to $6583 \mathrm{~K}$, which is in the moderate range of temperature.

As seen from Table 2, all strong spectral lines of Ca specified in the figure are resonant, and consequently, it is expected they are prone to the self-absorption phenomenon. But among these three lines, the emission line of $422.673 \mathrm{~nm}$, because of a larger S/N, appears to be more appropriate to use in calculations. About this issue, we will discuss further.

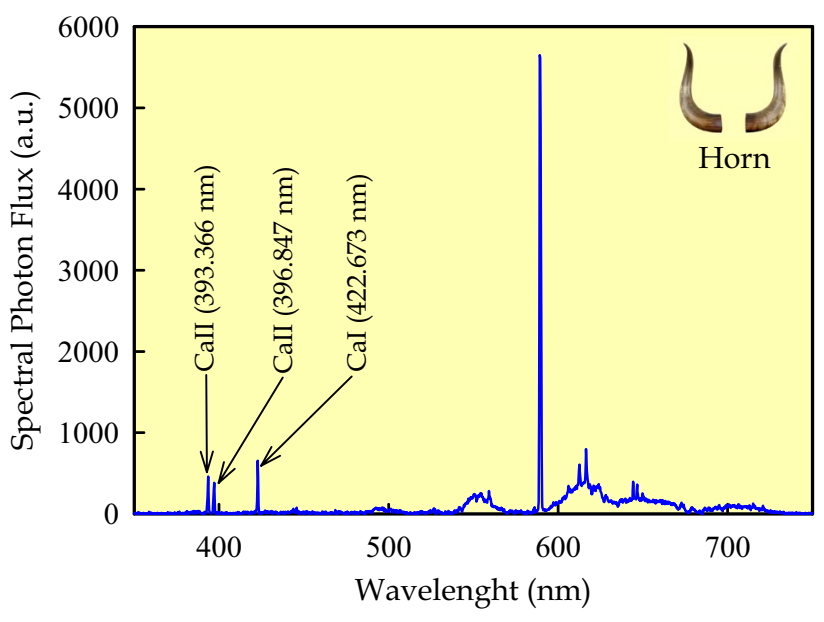

Fig. 4 The plasma emission spectrum of horn matrix measured by LIBS experiment

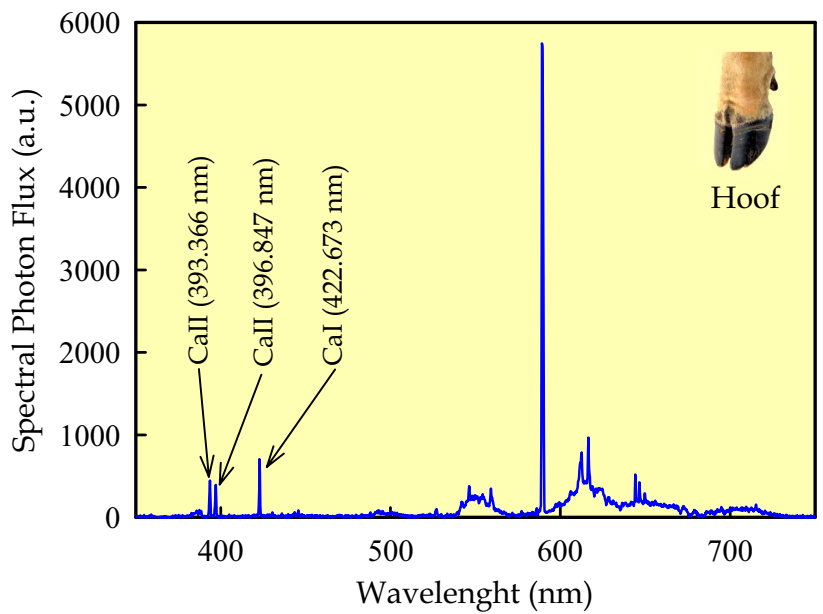

Fig. 5 The plasma emission spectrum of hoof matrix measured by LIBS experiment

In order to measure the calcium concentration of nails, as mentioned earlier, the calibration-based method was utilized considering cow's horn and hoof as the matrices. But the plasma emission spectra of these matrices (Figs. 4, 5) indicated that they, before adding any materials, have some calcium.

Therefore, the calcium concentration of the matrices was initially measured by the method of standard additions. For this purpose, first, the signal $\left(\bar{S}_{\mathrm{A}-\mathrm{st}}\right)$ of the spectral line of $422.673 \mathrm{~nm}$ related to $\mathrm{Ca}$ as the analyte was obtained from the experimental spectrum of each sample (as recorded in columns 5 and 10 of Table 1). Then, for each matrix, the signals were normalized with respect to the signal of analyte in the pure matrix (columns 6 and 11 of Table 1); and a linear calibration curve was established by plotting 


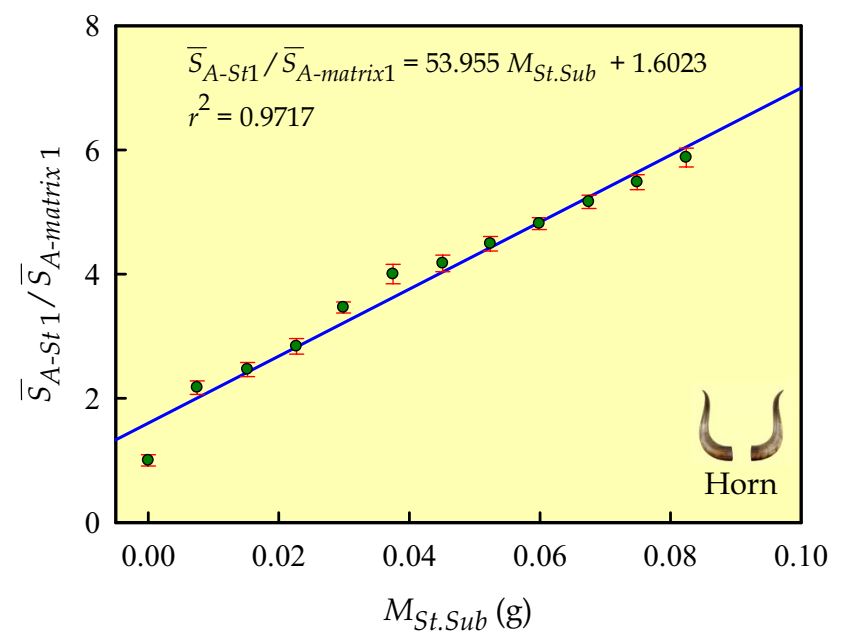

Fig. 6 The linear calibration curve established by the normalized signals versus masses of standard substance added to horn matrix

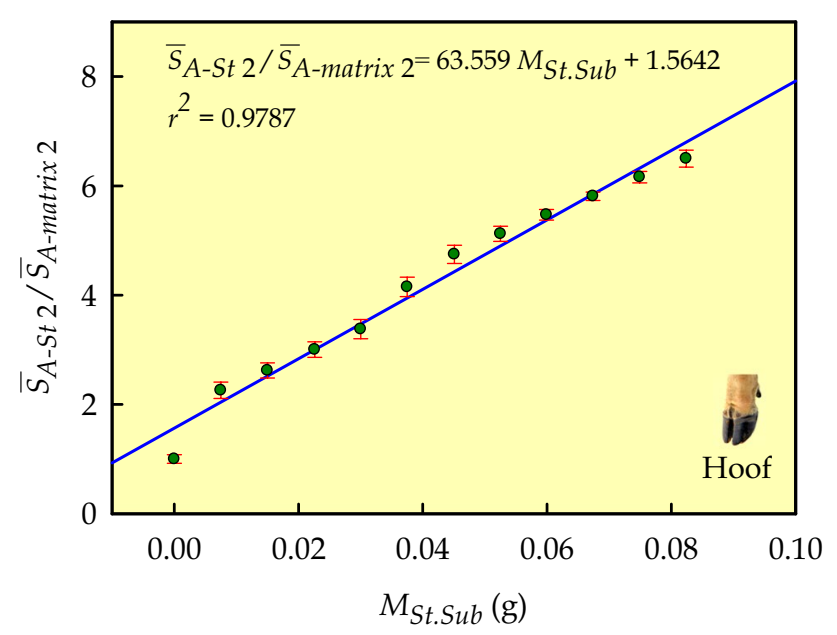

Fig. 7 The linear calibration curve established by the normalized signals versus masses of standard substance added to hoof matrix

normalized signals $\left(\left(\bar{S}_{\mathrm{A}-\mathrm{st}}\right)_{j} / \bar{S}_{\mathrm{A} \text {-matrix }}\right)$ versus masses of standard substance $\left(\left(M_{\text {st.sub }}\right)_{j}\right)$ added to each matrix (Figs. 6, 7). Finally, the calcium concentration of each matrix $\left(C_{\mathrm{A}-\text { matrix }}\right)$ was calculated from the slope $(a)$ of the linear calibration curve via the following equation [9],

$a=\frac{1}{M_{s t}}\left(\frac{C_{\mathrm{A}-\mathrm{st} . \text { sub }}}{C_{\mathrm{A}-\text { matrix }}}-1\right)$

In this equation, $M_{\mathrm{st}}$ is the total mass of the $j$ th standard sample which has been considered the same for all samples $(\sim 1.5000 \mathrm{~g})$, and $C_{\mathrm{A}-\mathrm{st} . \mathrm{sub}}$ is the mass fraction of the analyte $(\mathrm{Ca})$ in the standard substance $\left(\mathrm{CaCO}_{3}\right)$ that is

$C_{\text {A-st.sub }}=\frac{M_{\mathrm{Ca}}}{M_{\mathrm{CaCO}_{3}}}=\frac{40.078 \mathrm{~g} / \mathrm{mol}}{100.087 \mathrm{~g} / \mathrm{mol}}=0.400432$
Accordingly, by the use of Eq. (1) and the amounts of $a$ from Figs. 5 and 6, the calcium concentration of the two matrices (horn and hoof) was obtained equal to $C_{\mathrm{A}-\text { matrix } 1}=0.4887 \mathrm{wt} \%$ and $C_{\mathrm{A}-\text { matrix } 2}=0.4156 \mathrm{wt} \%$.

Having determined the calcium concentration of matrices, one can specify this quantity in the fingernail using the method of modified external standardization. In this method, as mentioned earlier, in order to determine the relationship between the measured signal of each spectral line and the concentration of the analyte, several certified standard samples with matrices generally different from but very similar to that of the target sample and with various predefined concentrations of the analyte should normally be prepared. Therefore, by measuring the plasma emission spectrum of each standard sample (e.g., the sample $j$ ), the method's sensitivity $(K)$ can be obtained from the following relation

$\left(\bar{S}_{\mathrm{A}-\mathrm{st}}\right)_{j}=K\left(C_{\mathrm{A}-\mathrm{st}}\right)_{j}$

where $C_{\mathrm{A}-\mathrm{st}}$ is the concentration of the analyte in the standard sample and $\bar{S}_{\mathrm{A}-\mathrm{st}}$ is its corresponding signal. On the other hand, for the target, one can write

$\bar{S}_{\mathrm{A}-\operatorname{tar}}=K C_{\mathrm{A}-\mathrm{tar}}$.

and eventually by omitting $K$ from Eqs. 2 and 3, the concentration of analyte in the target $\left(C_{\mathrm{A}-\operatorname{tar}}\right)$ is immediately derived from

$C_{\mathrm{A}-\mathrm{tar}}=\frac{\bar{S}_{\mathrm{A}-\mathrm{tar}}}{\left(\bar{S}_{\mathrm{A}-\mathrm{st}}\right)_{j}}\left(C_{\mathrm{A}-\mathrm{st}}\right)_{j}$

This approach, known as single-point external standardization or single-point normal calibration, is the least desirable way to standardize a method. When using a single standard sample, all experimental errors, both determinate and indeterminate, are carried over into the calculated value for $K$. This results in an uncertainty in the concentration of the target's analyte especially for the case that $K$ is not constant in different concentrations. Hence, in order to overcome the associated problems, the multiple-point standardization should be utilized with at least three standards, although more are preferable. A plot of $\left(S_{\mathrm{A}-\mathrm{st}}\right)_{i} \operatorname{versus}\left(C_{\mathrm{A}-\mathrm{st}}\right)_{i}$ for $i=1,2,3, \ldots n$ is known as a normal calibration curve. Here, as seen in Table 1, 11 samples have been prepared for each matrix. In order to calculate the calcium concentration in each sample, one should note that the total mass of calcium (the analyte) in each sample is the sum of ones in the corresponding matrix $\left(m_{\mathrm{A} \text {-matrix }}\right)_{j}$ and the standard substance $\left(m_{\mathrm{A}-\mathrm{st} . s u b}\right)_{j}$, that is,

$\left(m_{\mathrm{A}-\mathrm{tot}}\right)_{j}=\left(m_{\mathrm{A}-\mathrm{matrix}}\right)_{j}+\left(m_{\mathrm{A} \text {-st.sub }}\right)_{j}$

But, 
Table 3 The total calcium concentration of the standard samples for the two matrices (horn and hoof) and their corresponding signals and error bars

\begin{tabular}{lllllll}
\hline Sample no. & $\begin{array}{l}\left(C_{\mathrm{A}-\mathrm{st}}\right)_{j} \\
\text { Horn }(\mathrm{ppm})\end{array}$ & $\begin{array}{l}\left(\bar{S}_{\mathrm{A}-\mathrm{st}}\right)_{j} \\
\text { Horn (a.u.) }\end{array}$ & $\begin{array}{l}\text { Error bar } \\
\text { Horn (a.u.) }\end{array}$ & $\begin{array}{l}\left(C_{\mathrm{A}-\mathrm{st}}\right)_{j} \\
\text { Hoof }(\mathrm{ppm})\end{array}$ & $\begin{array}{l}\left(\bar{S}_{\mathrm{A}-\mathrm{st}}\right)_{j} \\
\text { Hoof (a.u.) }\end{array}$ & $\begin{array}{l}\text { Error bar } \\
\text { Hoof } \\
\text { (a.u.) }\end{array}$ \\
\hline 2 & 6440 & 660.5 & 33.2 & 6137 & 646.3 & 43.3 \\
3 & 8499 & 749.0 & 34.9 & 8119 & 750.0 & 39.7 \\
4 & 10,479 & 862.4 & 38.1 & 10,127 & 859.8 & 40.9 \\
5 & 12,380 & 1052.9 & 26.6 & 12,082 & 966.8 & 50.8 \\
6 & 14,386 & 1216.4 & 47.6 & 14,063 & 1187.9 & 50.2 \\
7 & 16,392 & 1269.0 & 40.6 & 16,071 & 1358.0 & 47.7 \\
8 & 18,319 & 1365.4 & 35.7 & 18,026 & 1466.0 & 39.5 \\
9 & 20,298 & 1463.1 & 28.7 & 19,981 & 1565.8 & 28.3 \\
10 & 22,305 & 1570.0 & 32.8 & 21,962 & 1662.8 & 22.0 \\
11 & 24,259 & 1666.2 & 36.7 & 23,943 & 1762.9 & 30.3 \\
12 & 26,238 & 1787.2 & 46.5 & 25,925 & 1859.7 & 44.7 \\
\hline
\end{tabular}

$\left(m_{\mathrm{A}-\mathrm{tot}}\right)_{j}=\left(C_{\mathrm{A}-\mathrm{st}}\right)_{j}\left(M_{\mathrm{st}}\right)_{j}$,

$\left(m_{\text {A-matrix }}\right)_{j}=C_{\text {A-matrix }}\left(M_{\text {matrix }}\right)_{j}$ and

$\left(m_{\mathrm{A}-\mathrm{st} . \mathrm{sub}}\right)_{j}=C_{\mathrm{A} \text {-st.sub }}\left(M_{\mathrm{st.sub}}\right)_{j}$.

Thus, by inserting these equations into Eq. (5) and carrying out some trivial mathematical calculation, we have

$\left(C_{\mathrm{A}-\mathrm{st}}\right)_{j}=C_{\mathrm{A}-\text { matrix }}+\left(C_{\mathrm{A} \text {-st.sub }}-C_{\mathrm{A} \text {-matrix }}\right) \frac{\left(M_{\mathrm{st} . \mathrm{sub}}\right)_{j}}{\left(M_{\mathrm{st}}\right)_{j}}$

Table 3 indicates the total calcium concentration of the prepared samples using the two matrices, calculated by Eq. (6).

Figures 8 and 9 illustrate the normal calibration curves plotted using the data of Table 3 for horn and hoof matrices, respectively. Despite the self-absorption of calcium at the wavelength $422.673 \mathrm{~nm}$, in both cases, the signal of the spectral line of $422.673 \mathrm{~nm}$ approximately grows linearly with the concentration of calcium as easily seen from the coefficient of determination of both curves. This may be due to two reasons. First, the calcium concentration in the samples is fairly low. Second, the samples have been irradiated by a rather low laser energy $(26 \mathrm{~mJ})$, causing a nearly moderate plasma temperature $(6583 \mathrm{~K})$. Although the calibration curve slope of hoof matrix is slightly greater than that of horn one, the pure calcium concentration of the former $(0.4156 \mathrm{wt} \%)$ is partly lower than that of the latter (0.4887 wt\%).

Having specified the calibration curves related to the two matrices, one can determine the calcium concentration of a typical fingernail. For this purpose, three different types of fingernails belonging to people with different physical conditions and almost identical ages were selected to

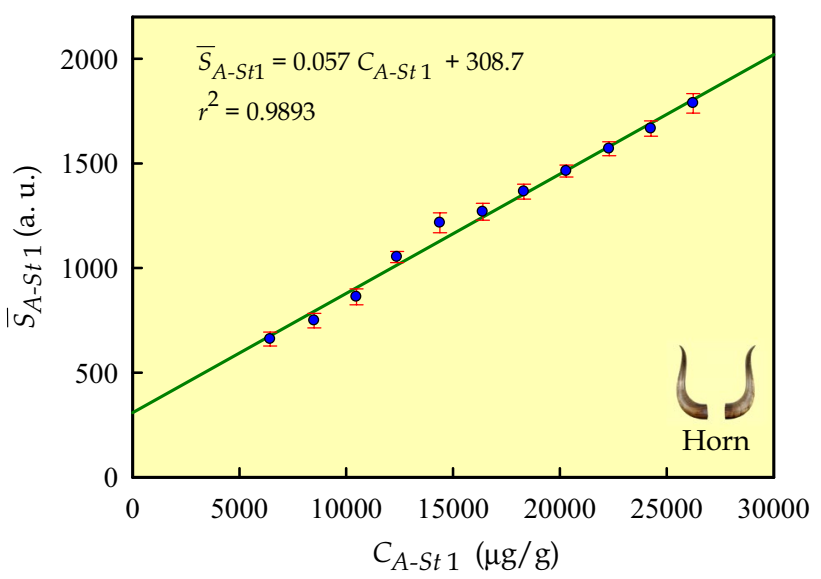

Fig. 8 The normal calibration curve with horn matrix created using the information of 12 standard samples. The ordinate is the signal of the spectral line of $422.673 \mathrm{~nm}$ of calcium, and the abscissa is the total calcium concentration

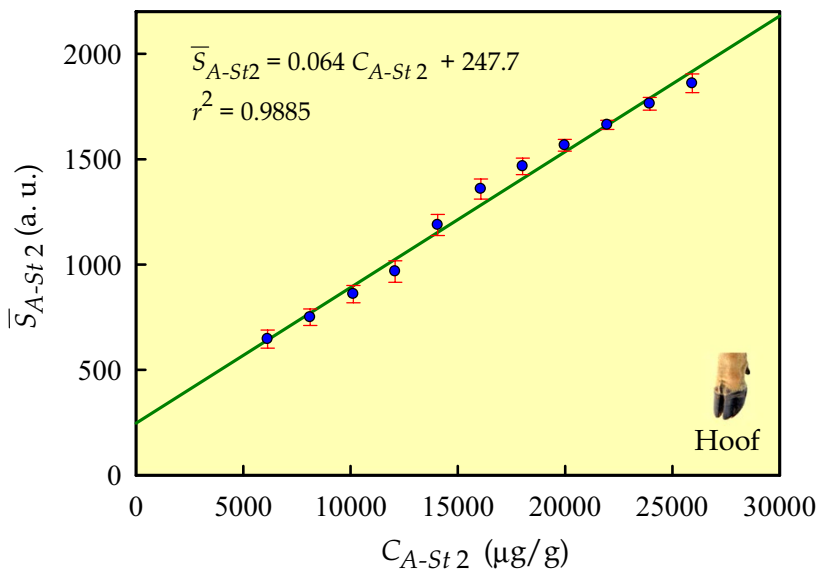

Fig. 9 The normal calibration curve with hoof matrix created using the information of 12 standard samples. The ordinate is the signal of the spectral line of $422.673 \mathrm{~nm}$ of calcium, and the abscissa is the total calcium concentration 
Table 4 The calcium concentration of fingernail for three different people: $C_{\mathrm{Ca}-\mathrm{Horn}}$ and $C_{\mathrm{Ca}-\mathrm{Hoof}}$ are fingernail calcium concentrations with horn and hoof matrices, respectively; $C_{\text {Ca-Average }}$ is the average calcium concentration. Signal is related to the spectral line of $422.673 \mathrm{~nm}$

\begin{tabular}{lclll}
\hline Person & $\begin{array}{l}\text { Signal } \\
(\text { a.u. })\end{array}$ & $\begin{array}{l}C_{\text {Ca-Horn }} \\
(\mathrm{ppm})\end{array}$ & $\begin{array}{l}C_{\mathrm{Ca}-H o o f} \\
(\mathrm{ppm})\end{array}$ & $\begin{array}{l}C_{\text {Ca-Average }} \\
(\mathrm{ppm})\end{array}$ \\
\hline 1 & 1185.6 & 15,384 & 14,564 & 14,974 \\
2 & 1072.7 & 13,402 & 12,809 & 13,106 \\
3 & 934.1 & 10,970 & 10,657 & 10,814 \\
\hline
\end{tabular}

be investigated. Table 4 indicates calcium concentrations related to the three specimens along with their averages, obtained by the two linear calibration curves. The signals have been measured by a laser energy equal to that was implemented in the standard samples. At this stage, there are two important points. Firstly, it should be noted that the discrepancy between the calcium concentration of specimens with horn matrix $\left(C_{\mathrm{Ca}-\mathrm{Horn}}\right)$ and hoof matrix $\left(C_{\mathrm{Ca}-\mathrm{Hoof}}\right)$ is in the range of 3-5 percent; signifying that this method can be, to a considerable extent, reliable to measure concentrations. Secondly, the difference between the average calcium concentrations $\left(C_{\mathrm{Ca} \text {-Average }}\right)$ of people may be due to their different physical conditions. In this case, the interesting thing is that, according to our survey, Person 1 consumes more dairy products than Person 2, and this is also similarly true for Person 2 relative to Person 3. Accordingly, this can be a confirmation that nails contain the history of human life quality.

\section{Conclusion}

In this research work, human fingernail was inspected by LIBS method. The plasma spectra indicated that there are a large number of elements in the fingernail, but $\mathrm{Ca}$, as an important mineral in supporting skeletal structure and function, was considered to be studied. Cow's horn and hoof, owing to their very similarity to the structure of human fingernail, were selected as matrices of the standard samples to be prepared. To construct the standard samples, $\mathrm{CaCO}_{3}$ was used as the standard substance containing the element $\mathrm{Ca}$ with the mass fraction of $0.400432 \mathrm{wt} \%$. Twelve standard samples with different amounts of the analyte $(\mathrm{Ca})$ were fabricated using each matrix (in total 24 samples). The plasma spectrum of all samples (in tablet forms) were measured through LIBS setup. Since the matrices, themselves, have some calcium before adding any standard substance, first of all, the calcium concentration of 0.4887 and $0.4156 \mathrm{wt} \%$ was, respectively, obtained for the matrices horn and hoof from the method of standard additions. Then, two normal calibration curves were created by plotting the signal versus the concentration of calcium, resulted in the modified external standardization. In both methods, standard additions and external standards, the signal of the spectral line $422.673 \mathrm{~nm}$ of calcium was considered as the parameter of the ordinate of diagrams. Finally, the fingernail calcium concentration of three people with different physical conditions was measured by the two linear calibration curves. The results obtained from horn and hoof matrices for each specimen are, with 3-5 percent error, identical. The review of the three people's diet proves that the fingernail calcium concentration of each person depends on their nutrition.

Open Access This article is distributed under the terms of the Creative Commons Attribution 4.0 International License (http://creativeco mmons.org/licenses/by/4.0/), which permits unrestricted use, distribution, and reproduction in any medium, provided you give appropriate credit to the original author(s) and the source, provide a link to the Creative Commons license, and indicate if changes were made.

\section{References}

1. Debras-Guédon, J., Liodec, N.: De l'utilisation du faisceau issu d'un amplificateur à ondes lumineuses par émission induite de rayonnement (laser à rubis), comme source énergétique pour l'excitation des spectres d'émission des éléments. CR Acad. Sci. Paris 257, 3336 (1963)

2. Tognoni, E., Palleschi, V., Corsi, M., Cristoforetti, G.: Quantitative micro-analysis by laser-induced breakdown spectroscopy: a review of the experimental approaches. Spectrochim. Acta B 57, $1115(2002)$

3. Sallé, B., Mauchien, P., Maurice, S.: Laser-induced breakdown spectroscopy in open-path configuration for the analysis of distant objects. Spectrochim. Acta B 62, 739 (2007)

4. Kolmhofer, P.J., Eschlböck-Fuchs, S., Huber, N., Rössler, R., Heitz, J., Pedarnig, J.D.: Calibration-free analysis of steel slag by laser-induced breakdown spectroscopy with combined UV and VIS spectra. Spectrochim. Acta B 106, 67 (2015)

5. Matsumoto, A., Tamura, A., Koda, R., Fukami, K., Ogata, Y.H., Thornton, B., Nishi, N., Sakka, T.: calibration-free approach for on-site multi-element analysis of metal ions in aqueous solutions by electrodeposition-assisted underwater laser-induced breakdown spectroscopy. Spectrochim. Acta B 118, 45 (2016)

6. Lasheras, R.J., Bello-Gálvez, C., Anzano, J.M.: Quantitative analysis of oxide materials by laser-induced breakdown spectroscopy with argon as an internal standard. Spectrochim. Acta B 82, 65 (2013)

7. McNaghten, E.D., Parkes, A.M., Griffiths, B.C., Whitehouse, A.I., Palanco, S.: Detection of trace concentrations of helium and argon in gas mixtures by laser-induced breakdown spectroscopy. Spectrochim. Acta B 64, 1111 (2009)

8. Bassiotis, I., Diamantopoulou, A., Roubani-Kalantzopoulou, F., Giannoudakos, A., Kompitsas, M.: Effects of experimental parameters in quantitative analysis of steel alloy by laser-induced breakdown spectroscopy. Spectrochim. Acta B 56, 671 (2001)

9. Shirvani-Mahdavi, H., Shafiee, P.: Quantitative analysis of soil calcium by laser-induced breakdown spectroscopy using addition and addition-internal standardizations. Meas. Sci. Technol. 27, 125502 (2016)

10. Zheng, L., Niu, S., Khan, A.Q., Yuan, S., Yu, J., Zenga, H.: Comparative study of the matrix effect in $\mathrm{Cl}$ analysis with 
laser-induced breakdown spectroscopy in a pellet or in a dried solution layer on a metallic target. Spectrochim. Acta B 118, 66 (2016)

11. Panne, U., Haisch, C., Clara, M., Niessner, R.: Analysis of glass and glass melts during the vitrification process of fly and bottom ashes by laser-induced plasma spectroscopy. Part I: normalization and plasma diagnostics. Spectrochim. Acta B 53, 1957 (1998)

12. Maury, C., Sirven, J.-B., Tabarant, M., L'Hermite, D., Courouau, J.-L., Gallou, C., Caron, N., Moutiers, G., Cabuil, V.: Analysis of liquid sodium purity by laser-induced breakdown spectroscopy. Modeling and correction of signal fluctuation prior to quantitation of trace elements. Spectrochim. Acta B 82, 28 (2013)

13. Lasheras, R.J., Bello-Gálvez, C., Anzano, J.M.: Quantitative analysis of oxide materials by laser-induced breakdown spectroscopy with argon as an internal standard. Spectrochim. Acta B 82, 65 (2013)

14. Chamcheu, J.C., Siddiqui, I.A., Syed, D.N., Adhami, V.M., Liovic, M., Mukhtar, H.: Keratin gene mutations in disorders of human skin and its appendages. Arch. Biochem. Biophys. 508, 123 (2011)

15. Wang, B., Yang, W., McKittrick, J., Meyers, M.A.: Keratin: structure, mechanical properties, occurrence in biological organisms, and efforts at bioinspiration. Prog. Mater Sci. 76, 229 (2016)

16. Karita, K., Takano, T., Nakamura, S., Haga, N., Iwaya, T.: A search for calcium, magnesium and zinc levels in fingernails of
135 patients with osteogenesis imperfecta. Trace Elem. Med. Biol. 15, 36 (2001)

17. Mehra, R., Juneja, M.: Fingernails as biological indices of metal exposure. J. Biosci. 30, 253 (2005)

18. Yesil, Y., Kuyumcu, M.E., Ozturk, Z.A., Ulger, Z., Sahin, U., Cankurtaran, M., Halil, M., Yavuz, B.B., Vural, H., Kara, Y., Demirin, H., Akyol, O., Ariogul, S.: The relationship between metabolic bone diseases and fingernail calcium levels in the elderly. Eur. Geriatr. Med. 3, 341 (2012)

19. Blaurock-Busch, E., Busch, Y.M., Friedle, A., Buerner, H., Parkash, C., Kaur, A.: Comparing the metal concentration in the nails of healthy and cancer patients living in the Malwa Region of Punjab, India with a random European group - a follow up study. Br. J. Med. Med. Res. 5, 480 (2015)

20. Pineda-Vargas, C.A., Mars, J.A., Gihwala, D.: Elemental concentration distribution in human fingernails-a 3D study. Nucl. Instrum. Methods Phys. Res. B 273, 153 (2012)

21. Przybylowicz, A., Chesy, P., Herman, M., Parczewski, A., Walas, S., Piekoszewski, W.: Examination of distribution of trace elements in hair, fingernails and toenails as alternative biological materials. Application of chemometric methods. Cent. Eur. J. Chem. 10, 1590 (2012) 